\title{
EVALUACIÓN AGROMORFOLÓGICA Y CARACTERIZACIÓN MOLECULAR DE LA ÑUNA (PHASEOLUS VULGARIS L.)
}

\author{
AGROMORPHOLOGICAL EVALUATION AND MOLECULAR \\ CHARACTERIZATION OF POPPING BEAN (PHASEOLUS VULGARIS L.)
}

\author{
José Cruz Balarezo ${ }^{1}$; Félix Camarena Mayta ${ }^{1}$; Jean Pierre Baudoin ${ }^{2}$; \\ Amelia Huaringa Joaquín ${ }^{1}$; Raúl Blas Sevillano ${ }^{1}$
}

\begin{abstract}
RESUMEN
La ñuña es una especie originaria de los Andes centrales, sus granos presentan alto contenido de proteínas y es consumida tostada. Se estudiaron 24 entradas, con el objetivo de determinar el nivel de duplicación del germoplasma de ñuña de la UNALM e identificar las entradas con mayor rendimiento de grano seco y calidad del grano tostado. La evaluación morfológica se realizó usando 30 descriptores agromorfológicos del frijol común y la caracterización molecular se hizo con la técnica RAPD, empleando seis iniciadores decaméricos. Según el análisis morfológico y molecular no se encontró duplicación de germoplasma en el material evaluado, y los dendogramas no forman grupos según el origen geográfico. Las entradas con mayor rendimiento de grano seco son UNALM-18, UNALM-16 y UNALM-15 con 1458.4, 1451.6 y $1337.4 \mathrm{~kg} / \mathrm{ha}$, respectivamente; mientras que las entradas con buena calidad de granos y mayor volumen de granos reventados son UNALM-15, UNALM-19 y UNALM-18 con $10.11,9.46$ y $7.04 \mathrm{ml}$ de expansión. Estas entradas tienen alta potencialidad para su explotación comercial, las que deberán priorizarse en los programas de mejoramiento genético con la finalidad de generar nuevas variedades que respondan a las exigencias de mercado. Esto puede generar mayores ingresos y mejorar las condiciones de vida de los agricultores andinos.
\end{abstract}

Palabras clave: caracterización morfológica, caracterización molecular, Phaseolus vulgaris, frijol ñuña, variabilidad genética.

\begin{abstract}
The popping bean ( $\tilde{n} u \tilde{n} a)$ is a species originated in the Andean central region, their seeds have high protein contain and are consumed toasted. A study was conducted on 24 accessions in order to determine the duplication level of nuña germplasm maintained at the UNALM, and to identify accessions with high dry seed yield and toasted seed quality. The morphological evaluation was made according to 30 descriptors of common bean; and the molecular characterization was made using RAPD technique, with 6 decameric primers. Morphological and molecular analyses did not reveal germplasm duplication in the evaluated material, and dendograms did not show clustering of accessions according to geographic origin. Accessions with high seed yield were UNALM-18, UNALM-16 and UNALM-15 with 1458.4, 1451.6 and $1337.4 \mathrm{~kg} / \mathrm{ha}$ respectively, whereas the accessions with good seed quality and the highest volume of burst grains are UNALM-15, UNALM-19 and UNALM-18 with expansion of 10.11, 9.46 and 7,04 ml. These accessions have high potentiality for their commercial exploitation and should be prioritized in plant breeding programs in order to create new varieties that respond to the market exigencies. This could generate greater incomes and improve the life quality of Andean farmers. variability.

Key words: morphological characterization, molecular characterization, RAPD, Phaseolus vulgaris, pop bean, genetic
\end{abstract}

\section{INTRODUCCIÓN}

La ñuña (Phaseolus vulgaris L.) es un cultivo originario de la región central de los Andes y tiene mucha importancia en la dieta nutricional del poblador rural andino. También es utilizada en la industria de la panificación y la confitería. Además del alto contenido de proteínas (alrededor de 20\%), contribuye al mejoramiento de los suelos, por su capacidad de fijar nitrógeno. Morfológicamente es el mismo que el frijol común, con la diferencia de que éste tiene la capacidad de reventar y aumentar de volumen cuando es tostado solo o en aceite. Se distribuye desde Cajamarca-Perú (latitud 7³0’ S)

1 Universidad Nacional Agraria La Molina, Ap. 456, Lima, Perú.

2 Faculté Universitaire des Sciences Agronomiques de Gembloux, Passage des Déportés, 2, B. 5030 Gembloux, Belgique.

Fecha de Recepción: 23 Enero 2007

Fecha de Aceptación: 10 Mayo 2007 
hasta Chuquisaca-Bolivia (latitud $19^{\circ} 30^{\prime} \mathrm{S}$ ), entre 1.900 a $2.900 \mathrm{~m}$ de altitud (Zimmerer, 1986; Toro, 1990). En el Perú la ñuña se cultiva en los departamentos de Cajamarca, Cuzco, Ancash, Huánuco, Apurímac, La Libertad y Ayacucho (Tohme et al., 1995). La ñuña es altamente sensible a la duración de la luz diurna y tiene fotoperiodo de días cortos (Gamarra et al., 1996). Se desarrolla bien a temperaturas que fluctúan entre 10 y $30{ }^{\circ} \mathrm{C}$, siendo la óptima $20{ }^{\circ} \mathrm{C}$; temperaturas menores de $5{ }^{\circ} \mathrm{C}$ y mayores de $25{ }^{\circ} \mathrm{C}$ pueden ser dañinas (Llique, 1993). El rendimiento de la ñuña está afectado por el largo período vegetativo (8 meses), hábito de crecimiento tipo IVb, susceptibilidad a las heladas y a la mayoría de enfermedades del frijol común, además no soporta las sequías (Gamarra et al., 1996).

La capacidad de reventar es una cualidad importante en los frijoles tipo ñuña, la cual depende de la variabilidad genética presente en la población y de factores no genéticos. Las ñuñas son tostadas en un tiempo de 5 a 10 minutos, cubriendo su superficie con aceite vegetal o animal, la testa se abre en dos o más partes entre los cotiledones, éstos revientan saliendo de la envoltura de la semilla y el producto resultante es suave y de sabor agradable. Es importante señalar que los factores que determinan la capacidad de reventar son desconocidos; sin embargo, se indica que la forma de la semilla, su cubierta inelástica, la cantidad y calidad del almidón almacenado pueden favorecer el reventado. Para Van Beem et al. (1992), el tamaño del grano está relacionado con el fenómeno de expansión, es decir, a mayor tamaño del grano la expansión será mayor, lo que trae como consecuencia incremento en los rendimientos. El Centro Internacional de Agricultura Tropical (CIAT) cuenta con 305 entradas de ñuña, que incluyen 283 entradas del Perú y 22 entradas de Bolivia (CIAT, 1980; Tohme et al., 1995).

En el Perú, el Programa de Leguminosas de Grano y Oleaginosas de la Universidad Nacional Agraria La Molina (PLGO-UNALM) cuenta con diversas entradas de ñuña que precisan ser evaluadas para seleccionar las más promisorias. También se requiere de una adecuada identificación de las entradas, para evitar la duplicación del material presente en el banco de germoplasma. Este trabajo tiene como objetivos: determinar el nivel de duplicación del germoplasma de ñuña PLGO-UNALM e identificar entradas de ñuña con mayor rendimiento de grano seco y calidad de grano tostado (reventado).

\section{MATERIALES Y MÉTODOS}

\section{MATERIAL GENÉTICO}

Se utilizaron 24 entradas de ñuña procedentes de Perú y Bolivia, conservadas en el Banco de Germoplasma de la UNALM (Tabla 1). El estudio tuvo dos etapas: la primera para la caracterización agromorfológica del material experimental, que se llevó a cabo en el distrito de Chiquian, provincia de Bolognesi, Departamento de Ancash- Perú $\left(10^{\circ} 08^{\prime} 54^{\prime \prime} \mathrm{S}, 7^{\circ} 09^{\prime} 16^{\prime \prime} \mathrm{O}\right.$ y $\left.3374 \mathrm{~m}\right)$ y la segunda etapa para la caracterización molecular (realizada en el laboratorio de Biología Molecular del Instituto de Biotecnología (IBT) de la UNALM), utilizando la técnica RAPD ("Random Amplified Polymorphic DNA" - Polimorfismo de ADN amplificado al azar).

\section{CARACTERIZACIÓN MORFOLÓGICA}

Para la caracterización de la ñuña se emplearon los descriptores de frijol común (Phaseolus vulgaris L.) propuesto por la International Board of Plant Genetic Resources (IBPGR, 1982; ahora IPGRI). Se utilizó un total de 30 descriptores (15 cualitativos y 15 cuantitativos), de los cuales tres parámetros son para calidad de grano tostado y tres para consistencia o textura de grano tostado (Tabla 2). El ensayo se instaló bajo un Diseño de Bloque Completo al Azar (DBCA), empleando 24 entradas con tres repeticiones, haciendo un total de 72 unidades experimentales. El modelo aditivo lineal fue: $y_{i j}=\mu+\beta_{i}+\tau_{j}+\varepsilon_{i j}$; donde $y_{i j}=$ valor de observación de la unidad experimental en el bloque $i$ y con el tratamiento $j, \mu=$ efecto medio, $\beta_{\mathrm{i}}=$ efecto del i-ésimo bloque, $\tau_{\mathrm{j}}=$ efecto del $j$-ésimo tratamiento, $\varepsilon_{\mathrm{ij}}=$ error experimental.

La siembra se realizó manualmente el 12 de diciembre del año 2000. La distancia entre surcos fue de $0,8 \mathrm{~m}$, entre golpes de $0,5 \mathrm{~m}$ y la profundidad de $4 \mathrm{~cm}$, dejando al final tres semillas/golpe. Luego, a los 14 días, se realizó la siembra del maíz (como soporte) entre los golpes de ñuña. La cosecha se realizó manualmente entre los meses de junio y agosto del 2001, cuando las vainas estaban secas y presentaban un color pajizo, arrancando las vainas y colocándolas en bolsas de papel. 
Tabla 1

Material vegetal utilizado en el presente trabajo

\begin{tabular}{|c|c|c|c|c|}
\hline Clave & Entrada & Nombre común & Origen & Procedencia \\
\hline 1 & UNALM-1 & Huanganco morado & Perú & Huánuco \\
\hline 2 & UNALM-2 & Margarita amarilla & Perú & Huánuco \\
\hline 3 & UNALM-3 & Yukishapa runtol & Perú & Huánuco \\
\hline 4 & UNALM-4 & Vincha negra & Perú & Huánuco \\
\hline 5 & UNALM-5 & Gorrioncito & Perú & Huánuco \\
\hline 6 & UNALM-6 & Hucracuipa ismanin & Perú & Huánuco \\
\hline 7 & UNALM-7 & Blanquilla & Perú & Huánuco \\
\hline 8 & UNALM-8 & Maleta 1 & Perú & Huánuco \\
\hline 9 & UNALM-9 & Maleta 13 & Perú & Huánuco \\
\hline 10 & UNALM-10 & Mallcash negro & Perú & Huánuco \\
\hline 11 & UNALM-11 & Margarita & Perú & Huánuco \\
\hline 12 & UNALM.12 & Numia chispas & Perú & Huánuco \\
\hline 13 & UNALM-13 & Blanca nieves & Perú & Huánuco \\
\hline 14 & UNALM-14 & Mullipa murum & Perú & Huánuco \\
\hline 15 & UNALM-15 & Llatino & Perú & Huánuco \\
\hline 16 & UNALM-16 & Paloma & Perú & Huánuco \\
\hline 17 & UNALM-17 & Puka mallcash & Perú & Huánuco \\
\hline 18 & UNALM-18 & Upa cashapa muron & Perú & Huánuco \\
\hline 19 & UNALM-19 & Ñuña & Perú & Cajamarca \\
\hline 20 & UNALM-20 & Nuña morado & Perú & Huánuco \\
\hline 21 & UNALM-21 & Pechuy paloma & Perú & Huánuco \\
\hline 22 & UNALM-22 (G23616) & Poroto gris & Bolivia & CIAT \\
\hline 23 & UNALM -23 (G23619) & Poroto & Bolivia & CIAT \\
\hline $24 *$ & UNALM-24 (G23617) & Poroto & Bolivia & CIAT \\
\hline
\end{tabular}

* No incluido en el análisis molecular (RAPD), debido a la no disponibilidad de foliolos para la extracción de ADN

\section{CARACTERIZACIÓN MOLECULAR}

\section{EXTRACCIÓN DEL ADN}

La extracción de ADN se realizó a partir de los foliolos tiernos y frescos, según el método $\mathrm{CTAB}$ (Bromuro de hexadecil trimetil amonio), a pequeña escala de Doyle \& Doyle (1990), aplicado para la extracción de papa y camote (CIP, 1998).
La concentración y calidad de ADN se determinó por comparación con el marcador de peso molecular DNA $\lambda$ digerido con Hind III, en geles de agarosa al $0,8 \%$ y un buffer de corrida NEB (1X). Se ajustaron las concentraciones de ADN de todas las entradas a $4 \mathrm{ng} / \mu \mathrm{l}$, diluyendo en stock de $1 \mathrm{ml}$ de agua millipore, para luego hacer la amplificación PCR. 
Tabla 2

Descriptores y sus estados utilizados en el presenta trabajo

\section{Descriptores del frijol y sus estados}

1. Días a la floración: se evaluó desde la emergencia hasta que el $50 \%$ de las plantas tengan flores abiertas.

2. Forma de bractéola: 3 lanceolada, 5 intermedia, 7 ovada (la evaluación se realizó al momento de la floración).

3. Color de alas: 1 blanco, 2 verde, 3 lila, 4 blanco con franja carmín, 5 blanco con franja lila, 6 fuertemente avenado en rojo a lila oscuro, 7 rojo claro a lila oscuro, 8 lila con venas oscuras, 9 púrpura (se evaluó en flores abiertas).

4. Color de estandarte: 1 blanco, 2 blanco con borde lila, 3 blanco con franja roja, 4 blanco borde verde, 5 verde, 6 lila, 7 lila oscuro con borde exterior púrpura, 8 lila oscuro con puntos purpúreos, 9 púrpura, 10 rojo carmín.

5. Color de cáliz y bractéola: 1 verde, 2 violeta claro, 3 púrpura oscuro (se determinó al momento de la floración).

6. Hábito de crecimiento: 1 I arbustivo determinado, 2 II arbustivo indeterminado, 3 III indeterminado postrado con una o varias guías largas con ninguna o muy poca aptitud para trepar, 4 IV indeterminado con guía larga y trepadora.

7. Color de vainas a la fructificación: 1 amarillo pálido a blanco, 2 oro amarillo intenso, 3 verde normal, 4 verde brillante, 5 verde opaco a gris plateado, 6 rosado oscuro, 7 franja púrpura en verde, 8 franja carmín en verde, 9 franja rojo pálido en verde, 10 rojo carmín, 11 púrpura oscuro, 12 verde con moteaduras púrpura (se observó en vainas inmaduras completamente extendidas).

8. Días a la cosecha: días desde la siembra hasta que el $90 \%$ de las vainas listas para la cosecha.

9. Longitud de vainas: medida en mm de vainas completamente expandidas de plantas tomadas al azar.

10. Color de vainas a madurez fisiológica: 1 amarillo pálido a blanco, 2 oro amarillo intenso, 3 verde normal, 4 verde brillante, 5 verde opaco a gris plateado, 6 rosado oscuro, 7 rayado púrpura en verde, 8 rayado carmín en verde, 9 rayado rojo pálido en verde, 10 rojo carmín, 11 púrpura oscuro, 12 amarillo pálido con moteaduras púrpuras, 13 amarillo pálido con moteaduras negras, 14 púrpura claro con moteaduras amarillas (se observó directamente en plantas de la unidad experimental).

11. Vainas por planta: en promedio de plantas tomadas al azar.

12. Granos por vainas: se contaron los granos en promedio de 10 vainas.

13. Lóculos por vaina: se evaluó el número de lóculos de 10 vainas tomadas al azar.

Evaluación de la semilla:

14. Brillo: 3 opaco, 5 satinado, 7 brillante.

15. Forma: 1 redonda, 2 ovalada, 3 cuboide, 4 arriñonada, 5 ahusada de lado truncado (se tomó de la mitad de la vaina).

16. Modelo de cubierta de semilla: 0 modelo ausente, 1 modelo monocoloreado, 2 modelo bicoloreado, 3 modelos de diferentes colores.

17. Tipo de modelo de cubierta de semilla: 0 ausente, 1 moteado constante, 2 rayado, 3 manchado romboide, 4 punteado, 5 moteado circular, 6 patrón de color circular 7 rayado externo, 8 manchado irregular, 9 modelo alrededor del hilum.

18. Color del fondo de la cubierta del grano: 1 blanco puro, 2 blanquecino, 3 blanco con matiz púrpura, 4 amarillo a amarillo verdoso, 5 verde clorofila, 6 verde, 7 crema pálido (bayo), 8 rosado, 9 rojo, 10 marrón amarillento, 11 gris, pardo marrón verdeado, 12 castaño, 13 púrpura, 14 morado, 15 negro (es el color predominante).

19. Color del modelo de la cubierta de la semilla: 0 ausente, 1 blanco puro, 2 blanquecino, 3 blanco con matiz púrpura, 4 amarillo a amarillo verdoso, 5 verde clorofila, 6 verde, 7 crema pálido (bayo), 8 rosado, 9 rojo, 10 marrón amarillento, 11 gris, pardo marrón verdoso, 12 castaño, 13 púrpura, 14 negro, 15 otros (es el color de las pintas que acompañan al color predominante).

20. Dimensión del grano: se tomó en mm, promedio de 10 granos de cada planta comprendido por parcela: Largo (paralelamente al hilum), ancho (del hilum al lado opuesto), espesor (medido perpendicular al hilum).

21. Rendimiento: se determinó el rendimiento por parcela y luego se llevó a hectárea.

22. Peso de 100 granos: se determinó para cada parcela incluida en los bloques, con 12 a $14 \%$ de humedad.

23. Volumen de 10 granos secos/ planta: se determinó en mililitros medido en un tubo probeta con alcohol al $96 \%$.

24. Volumen 10 granos reventados por planta: las mismas semillas usadas para medir el volumen en seco fueron tostadas y una vez reventados se determinó el volumen nuevamente de los 10 granos.

25. Porcentaje de expansión de los granos: es el volumen de 10 granos reventados entre volumen de granos sin reventar $\mathrm{x} 100$.

Evaluación de calidad de grano seco:

26. Rendimiento de grano seco: se determinó el rendimiento de las 3 parcelas y luego se llevó a una hectárea.

27. Volumen granos reventados: se obtuvo un valor promedio de las repeticiones y luego se realizó el análisis de variancia y la prueba de Duncan.

28. Porcentaje volumen de grano expandido: se obtuvieron valores promedios de cada repetición, con los que se realizó el análisis de variancia y la prueba de Duncan.

Calidad de grano tostado: se tomaron en consideración dos variables tal como lo hiciera Gallegos (1988).

29. Calidad de grano al tostado: 1 mal reventado, 2 intermedio, 3 buen reventado.

30. Consistencia del grano tostado o textura: 1 consistencia muy dura (apenas masticable), 2 consistencia intermedia (aceptable), 3 consistencia suave (buena aceptación al gusto). 


\section{ANÁLISIS RAPD}

Se empleó la técnica de RAPD siguiendo los procedimientos descritos por Williams et al. (1993). Esta técnica está basada en la amplificación específica de ADN por iniciadores diseñados al azar, mediante la PCR (reacción en cadena de la polimerasa).

Para la reacción PCR se utilizó una mezcla de reacción de $14 \mu \mathrm{l}$ en volumen $(8 \mu \mathrm{l}$ de la mezcla de los componentes de amplificación: $1.5 \mu \mathrm{l}$ de buffer $1 \mathrm{X}$, $1.8 \mu \mathrm{lde} \mathrm{MgCl}_{2}(3 \mathrm{mM}), 1.5 \mu \mathrm{ldNTPs}(0.25 \mathrm{mM})$, $3 \mu \mathrm{l}$ Primers $(0.5 \mu \mathrm{M}), 0.2 \mu \mathrm{l}$ Taq polimerasa $(1.5$ Unid.) y $6 \mu \mathrm{l}$ de $\mathrm{ADN}$ genómico a una concentración de $4 \mathrm{ng} / \mu \mathrm{l})$. En la placa de amplificación, primero se colocaron los componentes de amplificación, en seguida se añadió el ADN genómico y se cubrió esta mezcla con una gota de aceite mineral $(2.5 \mu \mathrm{l})$ para evitar la evaporación. La amplificación se realizó en un termociclador GeneAmp® System 9700 Applied Biosystems (Perkin Elmer, C. T. USA), según el siguiente programa de aproximadamente 3 horas de duración: 1 ciclo a $94{ }^{\circ} \mathrm{C} / 2 \mathrm{~min} ; 3$ ciclos a $94{ }^{\circ} \mathrm{C} / 1$ $\mathrm{m}, 37^{\circ} \mathrm{C} / 1 \mathrm{~m}, 72{ }^{\circ} \mathrm{C} / 1 \mathrm{~min}$ y $20 \mathrm{~s}$; y 37 ciclos a $94{ }^{\circ} \mathrm{C} / 35 \mathrm{~s}$ a $40{ }^{\circ} \mathrm{C} / 40 \mathrm{~s}$ y a $72{ }^{\circ} \mathrm{C} / 1 \mathrm{~min}$ y $20 \mathrm{~s}$; y la extensión final a $72^{\circ} \mathrm{C} / 7 \mathrm{~min}$. Se probaron en total 36 iniciadores decaméricos (kits A, B, S), los cuales fueron obtenidos de Operon Technologies (Alameda C.A. USA).

Los productos de amplificación (PCR) se separaron por electroforesis horizontal en geles de agarosa al 1,4\% en buffer $1 \mathrm{X}$ NEB (Tris $1 \mathrm{M}$, EDTA $10 \mathrm{mM}$, aceto de $\mathrm{Na} 3 \mathrm{H}_{2} \mathrm{O} 125 \mathrm{mM}$, pH 8.1). A los productos amplificados se añadieron $5 \mu \mathrm{lde}$ la solución tampón de carga (blue juice). Luego se cargaron $20 \mu \mathrm{l}$ de la reacción PCR en los pozos del gel. El gel se llevó a la cámara electroforética (Modelo 192 BioRad sub-cell Power PAC 3000, conteniendo $2500 \mathrm{ml}$ de buffer de conducción eléctrica $1 \mathrm{X}$ NEB y se corrió a 80 voltios por tres horas. El marcador de peso molecular usado en cada electroforesis fue ADN del fago $\lambda$ cortado con Hind III (patrón de fragmentos de tamaño conocido de 50-2000 pb).

La visualización del ADN se realizó sumergiendo el gel durante 30 minutos en la solución de bromuro de etidio $(0.5 \mathrm{mg} / \mathrm{mL})$, luego se enjuagó con agua destilada por 20 minutos. La imagen del gel se visualizó en un transiluminador con luz ultravioleta $(312 \mathrm{~nm})$, y esta fue captada por una cámara digital y almacenada en una computadora. La evaluación de las bandas se realizó usando el programa de visualización de imágenes Adobe Photo Shop 5.0; en ellas se buscó el polimorfismo, según la presencia o ausencia de las bandas en toda la población estudiada. Los datos fueron tabulados en hojas de cálculo Microsoft Excel versión 7. Los datos fueron analizados según el tipo de marcador estudiado.

\section{ANÁLISIS DE CARACTERES MORFOLÓGICOS}

Los datos fueron estudiados a través de técnica estadística básica como promedio, desviación estándar y el análisis de variancia (ANVA), para lo cual se utilizó Minitab 13.31.

Tambien se usaron técnicas multivariadas, como el análisis de agrupamiento (cluster analysis) utilizando el programa NTSYS pc 2.1 (Numerical taxonomy system) (Rohlf, 2000). Para ello, con los datos compilados según los estados de los descriptores (Tabla 2), se construyó una matriz de 24 entradas x 30 caracteres. Esta matriz se estandarizó debido a diferentes tipos de las variables analizadas; luego se obtuvo la matriz de distancias, respecto a cada par posible de entradas o unidades taxonómicas operativas (OTUs), mediante el coeficiente de distancia (Average taxonomic Distance - Distancia Euclidiana Promedio). Con este matriz de coeficiente de distancia taxonómica se realizaron agrupamientos (cluster analysis) a través de la técnica de ligamiento promedio aritmético "no ponderado", UPGMA (unweighted pair-group method using arithmetic averages), usando el procedimiento SAHN - clustering, incluido en NTSYS pc 2.1 (Rohlf, 2000).

\section{ANÁLISIS DE MARCADORES MOLECULARES}

A fin de determinar la capacidad de cada iniciador para detectar loci polimórficos en el germoplasma, se usó el PIC $=1-\sum p_{i}^{2}$ (contenido del índice de polimorfismo), donde $\mathrm{p}_{\mathrm{i}}$ es la frecuencia del i-ésimo alelo (Ghislain et al., 1999). El valor del PIC para cada marcador RAPD generado por el mismo iniciador fue acumulado y se llamó índice del marcador RAPD.

Los datos fueron compilados como presencia (1) o ausencia (0) de una banda. La carencia o duda de un dato se registró por 9 (denominación arbitraria). Con estos datos se formó una matriz de 23 entradas x 15 marcadores (loci); luego, se obtuvo la matriz de similitud, usando el coeficiente de asociación llamado "simple matching coefficient" (SMC), 
el cual da igual peso a $(0,0)$ y $(1,1)$ (Martínez, 1995). Con esta matriz de similitud se realizaron agrupamientos según los procedimientos UPGMA y SAHN-clustering.

\section{RESULTADOS Y DISCUSIÓN}

\section{ANÁLISIS AGROMORFOLÓGICOS}

Se observó una gran variabilidad en la mayoría de los rasgos morfológicos estudiados, particularmente en la forma, tamaño y color de los granos (Figura 1).

En rendimiento, las entradas evaluadas mostraron fluctuaciones entre 557.03 y $1.458 .44 \mathrm{~kg} / \mathrm{ha}$. Sin embargo, el análisis de variancia (ANVA) no mostró diferencias estadísticas entre tratamientos (Tabla 3). Las entradas de mayor rendimiento fueron UNALM18, UNALM-15 y UNALM-19 (con 1.458.44, 1.337 .45 y $884.27 \mathrm{~kg} / \mathrm{ha}$ respectivamente); mientras que las de menor rendimiento correspondieron a UNALM-16, UNALM-22 y UNALM-21 (con 557.03 y 601.05 y $666.56 \mathrm{~kg} / \mathrm{ha}$ respectivamente). Estos resultados son similares a los obtenidos en otros trabajos. Por ejemplo, Meléndez (1965), en un ensayo comparativo de cuatro variedades de ñuña, reportó rendimientos entre 0.758 y 1.496 t/ha. Gallegos (1988), al evaluar el comportamiento de 22 variedades de ñuña en condiciones de costa, bajo riego por goteo, obtuvo rendimientos de 1.25 a $2.59 \mathrm{t} / \mathrm{ha}$, el promedio de las 22 variedades de frijol ñuña fue de $1.82 \mathrm{t} / \mathrm{ha}$. Camarena et al. (1990), en la localidad de Acco-Huaraz, encontraron rendimientos de 0.3 a 1.4 t/ha. Asimismo Martínez (1991) obtuvo rendimientos que superaron las 0.70 t/ha con las variedades pava, maní, limona, jabona y crema. Por otro lado, la variedad Q'osqo poroto INIA, en asociación con maíz, tuvo un rendimiento promedio de $1.32 \mathrm{t} / \mathrm{ha}$ y en monocultivo $3.50 \mathrm{t} / \mathrm{ha}$; la variedad local Chec'che poroto obtuvo 0.691 t/ha en sistema asociado ñuña-maíz en evaluaciones

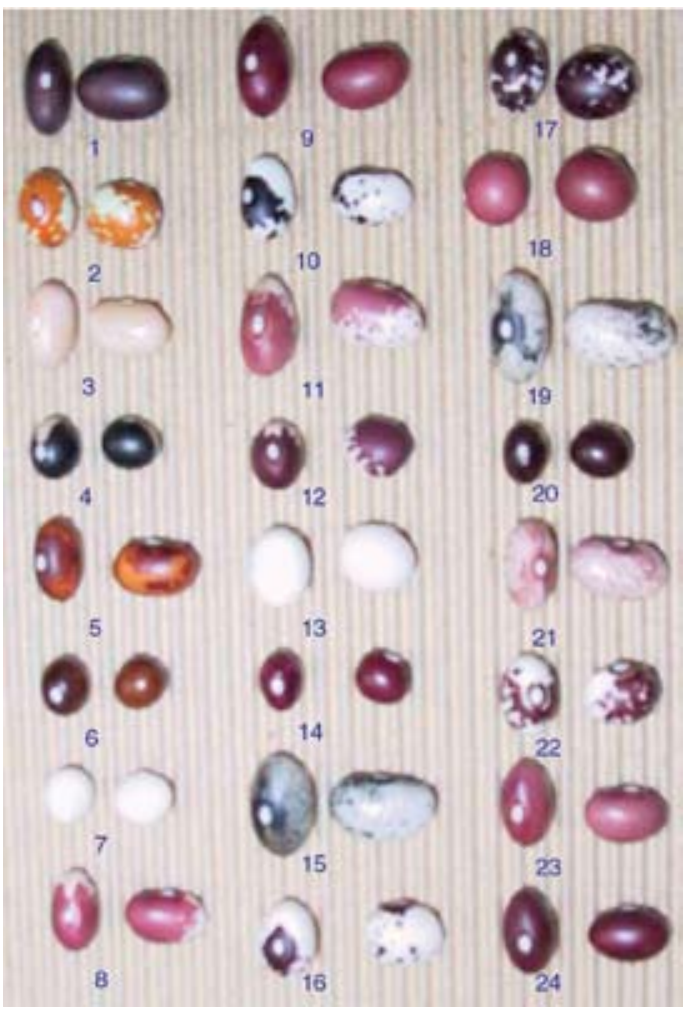

A. Coloración y forma de los granos crudos

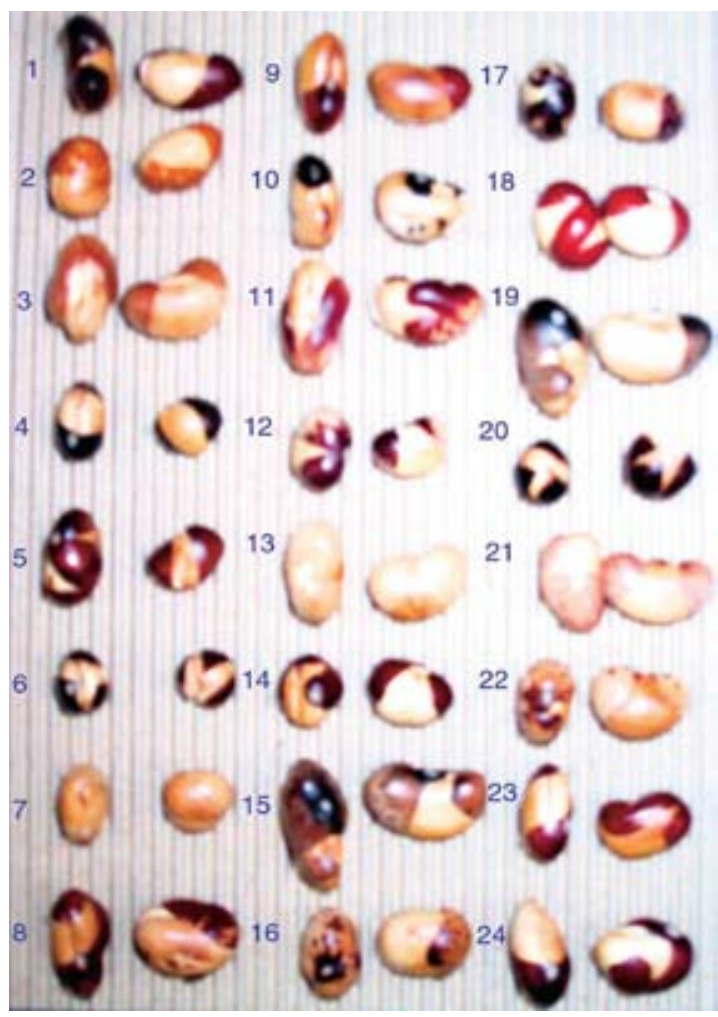

B. Granos tostados

Figura 1. Variabilidad morfológica de los granos y comportamiento en el tostado, de las 24 entradas de ñuña (la numeración corresponde al orden de las entradas, según la Tabla 1). 
realizadas en Cuzco (Gamarra et al.,1996). Una de las limitantes de rendimiento en las leguminosas de grano es la pérdida de las flores de alrededor de 70 a $80 \%$ como botones cerrados y frutos que caen prematuramente y sólo una pequeña parte llega a fruto maduro. Según estos resultados, la variabilidad del rendimiento nos sugiere que este carácter estaría muy influenciado por el ambiente, reportándose rendimientos que varían en promedio de 0.3 a $3 \mathrm{t} / \mathrm{ha}$. Esto sería por la pérdida de flores, que es un rasgo general de los frijoles.

En el análisis del volumen de 10 granos reventados, las entradas evaluadas muestran diferencias altamente significativas (Tabla 3); el mayor volumen se obtuvo en la entrada UNALM-15, seguido de UNALM-19 y UNALM-18 (con 10.11, 9.47 y 7.04 $\mathrm{ml})$. Mientras que las entradas con menor volumen fueron: UNALM-4, UNALM-7 y UNALM-6 (con $3.74,3.69$ y $3.37 \mathrm{ml}$ respectivamente). Los factores que dan lugar a las diferencias de expansión son el contenido de humedad, herencia de los genes, que condicionan un endospermo denso y elástico (Jugenheimer, 1981). Estas diferencias se pueden deber a la forma de la semilla, su cubierta inelástica, la cantidad y calidad de almidón almacenado (National Research Council, 1989).

Para el análisis del porcentaje de expansión de 10 granos reventados se obtuvieron diferencias significativas entre las entradas (Tabla 3). Las entradas con mayor porcentaje de expansión fueron: UNALM-18, UNALM-15 y UNALM-19 con $177.72,174.37$ y $171.96 \%$; y las de menor porcentaje de expansión fueron UNALM-1, UNALM-12 y UNALM-6 con 131.52, 131.62 y $135.74 \%$ respectivamente. Nuestros resultados son superiores a lo reportado por Alvarado (1997), quien encontró para el porcentaje de expansión como el más alto valor de $138.33 \%$ y el más bajo de $103.97 \%$ en la evaluación de las entradas conservadas en el banco de germoplasma de UNALM. Esto puede ser efecto ambiental, ya que han sido evaluados en diferentes localidades (Huarochiri, Lima) y tiempo. Estas diferencias de porcentaje también están en función del tamaño de grano, humedad de semilla. El grano con menor cantidad de humedad da mayor volumen de expansión que las recientemente cosechadas. También el tamaño promedio del grano de frijol ñuña se relaciona con el fenómeno de expansión, es decir, a mayor tamaño del grano la expansión será mayor (Van Beem et al., 1992). Consecuentemente, los genotipos con mayor expansión son de gran potencial para la industrialización.

\section{CALIDAD DE GRANO TOSTADO}

En este análisis se consideró la calidad de reventado (separación de testa y número de división de los cotiledones al reventar) y consistencia del grano tostado (textura). Se observó que 19 entradas presentaron buen reventado, los cotiledones se expanden en un $100 \%$ y la cáscara se separa fácilmente de la semilla; mientras que las cinco entradas restantes (UNALM-4, UNALM-6,

Tabla 3

Análisis de variancia del rendimiento, volumen y grado de expansión de granos reventados de las 24 entradas de ñuña

\begin{tabular}{|c|c|c|c|c|c|c|c|}
\hline \multirow{2}{*}{$\begin{array}{c}\text { Fuentes } \\
\text { de variación }\end{array}$} & \multirow{2}{*}{$\begin{array}{c}\text { Grados de } \\
\text { libertad }\end{array}$} & \multicolumn{2}{|c|}{$\begin{array}{c}\text { Rendimiento } \\
\text { (kg/ha) }\end{array}$} & \multicolumn{2}{|c|}{$\begin{array}{l}\text { Volumen de granos } \\
\text { reventados }(\mathrm{ml})\end{array}$} & \multicolumn{2}{|c|}{$\begin{array}{c}\text { Expansión de grano } \\
\text { reventados (\%) }\end{array}$} \\
\hline & & C.M. & $\operatorname{Pr}>F$ & C.M. & $\operatorname{Pr}>\mathrm{F}$ & C.M. & $\operatorname{Pr}>\mathrm{F}$ \\
\hline Bloque & 2 & 12.796 & $0.592 \mathrm{~ns}$ & 3.535 & $0.0001 * *$ & 1235.073 & $0.006 * *$ \\
\hline Tratamiento & 23 & 30.364 & $0.247 \mathrm{~ns}$ & 8.127 & $\begin{array}{c}<0.0001 * \\
*\end{array}$ & 470.479 & $0.0145^{*}$ \\
\hline Error & 46 & 24.095 & & 0.320 & & 220.933 & \\
\hline Total & 71 & & & & & & \\
\hline
\end{tabular}

$\mathrm{CM}=$ Cuadrados medios; $\mathrm{p}=$ Probabilidad, $\mathrm{ns}=$ no significativo $(\alpha>0.05), *=$ significativo $(\alpha<0.05)$,

$* *=$ altamente significativo $(\alpha<0.01)$ 
UNALM-7, UNALM-20 y UNLM-5) presentaron un reventado intermedio donde los granos se expanden en un 50 a $70 \%$, pero los cotiledones se dividen en varias partes y la cáscara no se separa fácilmente de la semilla. En la evaluación de la consistencia, 11 entradas (UNALM-6, UNALM-8, UNALM-9, UNALM-15, UNALM-16, UNALM-17, UNALM-18, UNALM-19, UNALM-22, UNALM23 y UNALM-24) presentaron consistencia suave (buena aceptación al gusto), 10 entradas presentaron consistencia intermedia (aceptable al gusto) y las tres entradas restantes (UNALM-5, UNALM-12 y UNALM-21) presentaron consistencia muy dura, apenas masticable. Esta misma tendencia se ha encontrado en otros trabajos de caracterización de germoplasma de ñuña, e.g. Meléndez (1965) y Van Beem (1992) encontraron diferencias en calidad y consistencia o blandura del grano tostado. En consecuencia, las entradas a la vez con buena calidad y suave consistencia fueron UNALM-8, UNALM-9, UNALM-15, UNALM-16, UNALM-17, UNALM-18, UNALM-19, UNALM-22, UNALM23 y UNALM-24.

En general, se observó que las entradas más sobresalientes en cuanto a rendimiento, volumen de grano reventado, porcentaje de expansión y calidad de grano tostado fueron: UNALM-18, UNALM-15, UNALM-19. Si bien es cierto que la entrada UNALM-19 no tiene alto rendimiento, pero se puede mejorar con un buen manejo agronómico del cultivo.

Por otro lado, existen otras entradas, como UNALM-6, que tienen buen rendimiento, pero bajo volumen de expansión, regular calidad de grano (revienta en varias partes), lo que no es aconsejable para la agroindustria. La variabilidad que se encuentra en estos caracteres es importante, ya que permitirá generar nuevas variedades con altos rendimientos en grano seco y volumen de expansión para diferentes localidades; además se debe buscar resistencia a plagas y enfermedades importantes de la ñuña.

\section{ANÁLISIS DE AGRUPAMIENTO SEGÚN DESCRIPTORES AGROMORFOLÓGICOS}

En el dendrograma (Figura 2), según los 30 descriptores agromorfológicos, se observa que no hay agrupamientos según origen geográfico. Las entradas procedentes de Perú y Bolivia (UNALM-22, UNALM-23, UNALM-24) forman grupos entre ellas; por ejemplo, la entrada boliviana UNALM-22 se acerca más a la entrada UNALM-16 de origen peruano, esto indicaría que genéticamente están muy relacionados algunos ecotipos de ñuña peruana con los bolivianos, ya que presentan características morfológicas bastante similares entre ellos. Lo mismo ocurre para las entradas procedentes de Perú (Cajamarca y Huánuco: UNALM-19 y UNALM-15 respectivamente); estas dos entradas son similares en tamaño, forma y color de semilla. Esto puede indicarnos que estos genotipos tienen amplia distribución o pueden ser también parte de las introducciones realizadas a través de trueques, comercio y/o introducciones de germoplasma por los investigadores.

Considerando un coeficiente de distancia 1.50, se forman tres grupos, el primero conformado por cuatro entradas (UNALM-6, UNALM-7, UNALM14 y UNALM-20) procedentes de Huánuco. Estas entradas presentan las siguientes características: granos redondos, pequeños (2.5-2.6 ml), granos de un solo color (rojo, blanco), mala calidad de grano tostado y precocidad (aproximadamente 180 días después de la siembra).

El segundo grupo es formado por dos entradas (UNALM-15 y UNALM-19), provenientes de Huánuco y Cajamarca. Sin embargo, comparten muchos caracteres agromorfológicos, tales como: forma de grano arriñonada, de granos grandes, calidad y expansión del grano luego del tostado muy buenas, volumen de grano seco (5.4-5.8 ml), número de granos por vaina promedio (4 semillas), peso de 100 semillas (49.9-58.4 g) y tardividad (aproximadamente cosecha a los 210 días después de la siembra).

El tercer grupo es conformado por las 18 entradas restantes, este material es procedente de Perú (Huánuco y Cajamarca) y Bolivia. Se caracterizan principalmente por tener granos opacos, a excepción de UNALM-6 que tiene grano brillante; sin embargo, es el grupo más heterogéneo que engloba tanto material precoz, longevo y muy variable en calidad de grano tostado.

Finalmente, si consideramos un coeficiente de distancia de cero, todas las entradas analizadas son diferentes, es decir, no hay duplicación de germoplasma, a pesar de que a nivel morfológico y color de granos algunas entradas son bastante parecidas, tales como las entradas UNALM-15 y UNALM-19. 


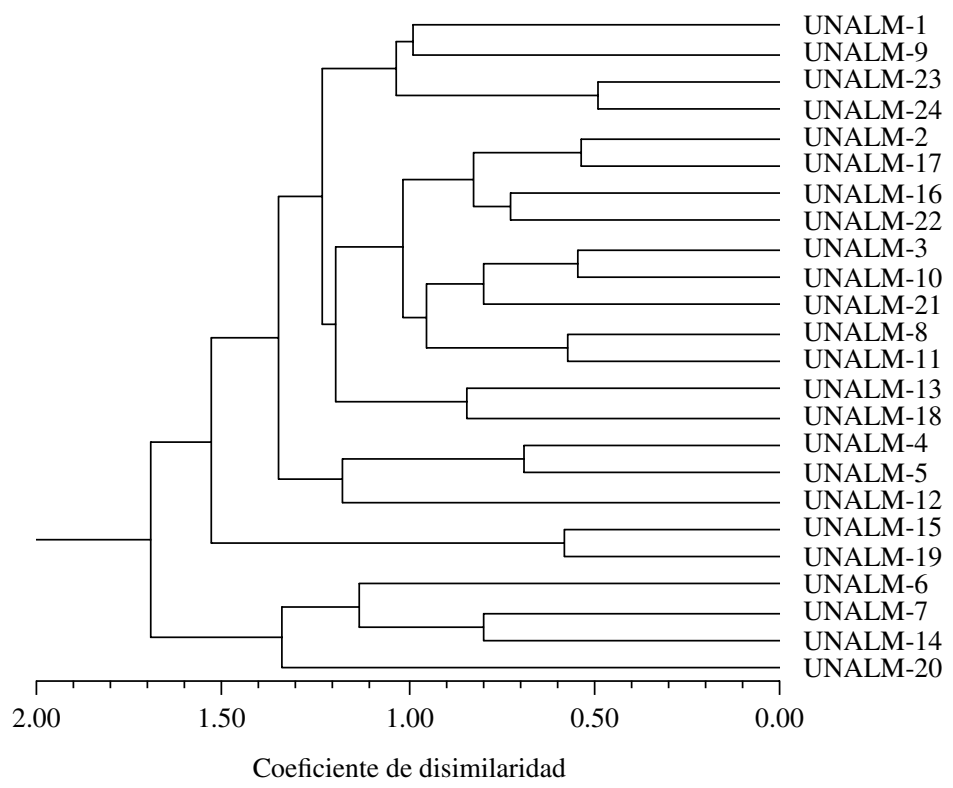

Figura 2. Dendrograma que agrupa a 24 entradas de ñuñas, según los 30 descriptores agromorfológicos.

\section{ANÁLISIS MOLECULAR}

\section{SELECCIÓN DE LOS INICIADORES}

Del total de 36 iniciadores decaméricos probados, sólo el $17 \%$ presentó polimorfismo en las amplificaciones (seis iniciadores). Estos iniciadores generaron pocas bandas polimórficas ( 15 fragmentos), de tamaños variables de 200 a $2000 \mathrm{pb}$ (Tabla 4). Esto significa que la mayor parte del genoma de las entradas analizadas son más homogéneas que heterogéneas para el grupo de iniciadores utilizados. Esto, a pesar de que existen características morfológicas bastante diferentes, pero que genéticamente podrían estar muy relacionadas. Estos resultados no son concluyentes porque el número de iniciadores utilizados son muy pocos, así como el número de las entradas empleadas. Para la ñuña, por ser autógama, es recomendable trabajar con mayor número de marcadores y entradas para tener resultados más precisos. Similares resultados han sido reportados en otras especies como la soya (Glycine $\max (\mathrm{L}$.) Merril), en la que se encontró bajo nivel de polimorfismo, lo que indica que tiene una limitada diversidad genética en los cultivos tradicionales, lo cual hace la identificación de marcadores más difícil (Khandka et al., 1996).

El PIC (contenido del índice de polimorfismo) varió entre 0.1 y 0.49 , el más alto valor de
PIC indica el marcador RAPD más informativo (Tabla 4). Según el índice del marcador RAPD, los iniciadores OPA-11, OPB-7, OPB-17 y OPA-10 son los mejores para detectar polimorfismo en ñuña, los que deberían ser usados de preferencia en futuras caracterizaciones de germoplasma.

\section{ANÁLISIS DE AGRUPAMIENTO CON MARCA- DORES RAPD}

En el dendrograma de la Figura 3, en general tampoco se forman grupos según la procedencia. Esto indicaría que los genotipos bolivianos pueden estar muy relacionados con las entradas de ñuñas huanuqueñas, posiblemente debido al mismo tipo de faseolina que presentan algunas entradas de Huánuco con los genotipos boliviano y cajamarquino. Similares resultados se han obtenido en el agrupamiento con los marcadores agromorfológicos. Este resultado presenta la misma tendencia que lo reportado para frijol común de Nicaragua, analizando la diversidad genética con marcadores microsatélite y morfológico, donde las variaciones a nivel molecular fueron explicadas por diferencias dentro y entre las razas, pero no entre las zonas agroecológicas (Gómez et al., 2004).

Considerando coeficiente de similitud de 0.6, se forman dos grupos. El primer grupo está for- 
Tabla 4

Iniciadores de secuencia aleatoria, número de fragmentos amplificados en ñuña

\begin{tabular}{|c|c|c|c|c|}
\hline \multirow{2}{*}{ Iniciador } & \multirow{2}{*}{ Secuencia $(\mathbf{5}, \mathbf{- 3}$ ') } & \multicolumn{2}{|c|}{ Número de fragmentos } & \multirow{2}{*}{ Indice del iniciador } \\
\cline { 3 - 5 } & & amplificados & polimórficos & \\
\hline \multirow{2}{*}{ OPA-10 } & GTGATCGCAG & 5 & 2 & 0.74 \\
OPA-11 & CAATCGCCGT & 6 & 5 & 1.87 \\
OPB-04 & GGACTGGAGT & 4 & 1 & 0.49 \\
OPB-07 & GGTGACGCAG & 5 & 3 & 0.82 \\
OPB-17 & AGGGAACGAG & 6 & 2 & 0.21 \\
OPS-03 & CAGAGGTCCC & 6 & 2 & \\
\hline Total & & $\mathbf{3 1}$ & $\mathbf{1 5}$ & \\
\hline
\end{tabular}

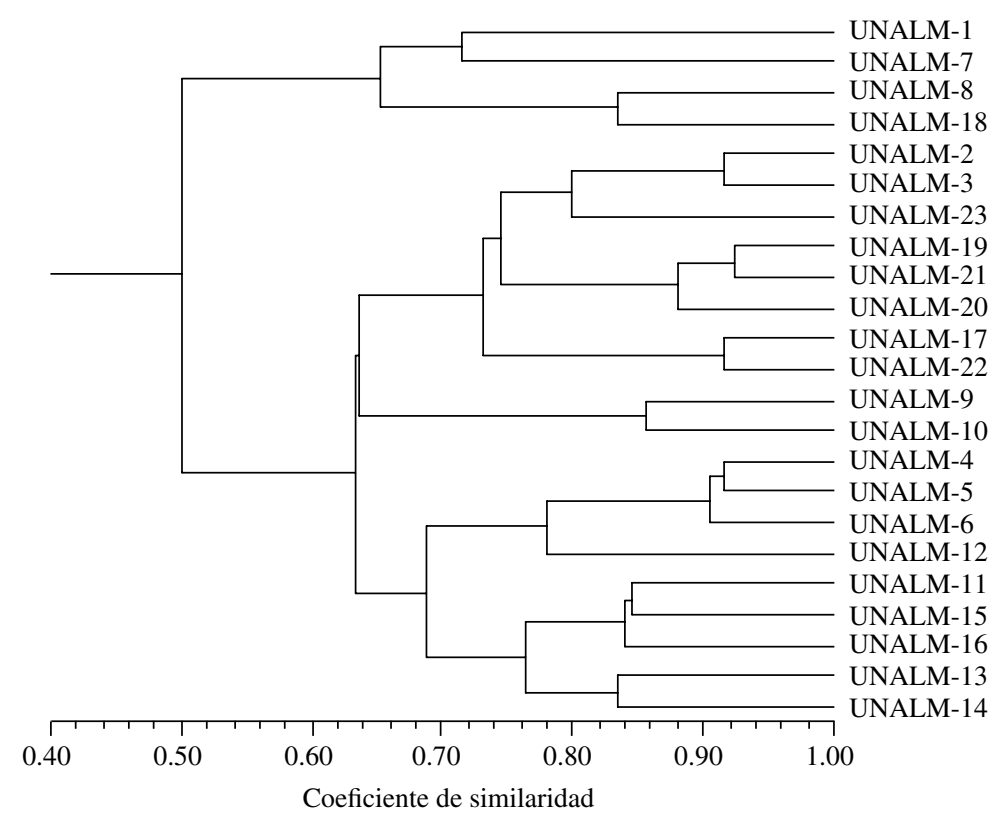

Figura 3. Dendrograma que agrupa 23 entradas de ñuña según los marcadores RAPD.

mado por cuatro entradas procedentes de Huánuco (UNALM-1, UNALM-7, UNALM-8 y UNALM-18). Estas entradas comparten caracteres morfológicos similares tales como: ancho, brillo, espesor, modelo, tipo de modelo y color de modelo de la cubierta de la semilla, días a la floración, días a la cosecha, peso de 100 semillas, tamaño y calidad de semilla. El segundo grupo está formado por todas las 19 entradas restantes, provenientes de Perú (Cajamarca y Huánuco) y Bolivia, las que se caracterizan por presentar la misma coloración de grano, brillo y tamaño de semilla, porcentaje de expansión, calidad de grano, días a la cosecha y días a floración. Sin embargo, a un coeficiente de similitud de 1.0, todos son diferentes, no hay duplicados en el germoplasma analizado, confirmándose el agrupamiento previo con los marcadores agromorfológicos.

Según los dendrogramas obtenidos a través de la caracterización agromorfológica y molecular (RAPD), no hay congruencia entre ellas. Como, por ejemplo, en los agrupamientos según la caracterización molecular se observa que UNALM-15 
con UNALM-19 se encuentran bastante distanciados a pesar de que éstos en la caracterización agromorfológica permanecen agrupados, ya que fenotípicamente presentan la misma forma, tamaño, color de granos, tienen los mayores volúmenes de expansión y calidad de grano reventado. Al respecto, Crisci y López (1983) manifiestan que nunca se obtiene una completa congruencia, pero tampoco una incompleta incongruencia, los valores varían según el grupo estudiado, características analizadas, método aplicado y forma en que se evalúa la congruencia. Existen causas biológicas y metodológicas como, por ejemplo, la diferencia de actividad de los genes en diferentes células de un organismo, plasticidad fenotípica, es decir, la posibilidad de que un mismo genotipo se exprese de distintas formas en ambientes diferentes, las mutaciones somáticas (dentro de un mismo individuo existen genotipos ligeramente diferentes); las causas metodológicas son aquellos pasos técnicos que pueden causar distorsiones como la determinación de homologías, la calidad y cantidad de características, la codificación, el tipo de evaluación de la congruencia, etc.

La caracterización molecular es más confiable que la caracterización morfológica, a pesar de ser muy pocos, puesto que estos no están influenciados por el medio ambiente, sin embargo en las entradas evaluadas aparentemente la diversidad molecular (genética) es menor que la diversidad morfológica. Este resultado confirma trabajos previos, e.g. Beebe et al. (2001) reportaron que a pesar de una vasta diversidad morfológica y de adaptación agroecológica existente en las razas andinas de frijol común, éstas tienen una base genética muy estrecha según los marcadores AFLP. Esto implicaría que las variedades andinas se derivan de una o de muy pocas poblaciones silvestres, posiblemente fueron domesticadas en las faldas orientales de los Andes de Bolivia; además la variabilidad morfológica existente entre las variedades nativas sería resultante de la selección del agricultor. También, nuestro material genético analizado corresponde solamente a una pequeña parte de la diversidad del frijol común: las variedades de ñuñas. También en maní (Arachis hypogea L.) se ha reportado amplia variabilidad morfológica y una estrecha base genética (Halward et al., 1992). Por otro lado, en otros cultivos de la región andina, como en el caso de maíz (Zea mays L.), tambien existiría mayor diversidad fenotípica que genética, donde muchas razas son distintas en sus caracteres morfológicos, pero están genéticamente muy relacionadas (Blas et al., 2002).

\section{CONCLUSIONES}

Según el análisis morfológico y molecular no hay duplicados de germoplasma, sin embargo, se ha evidenciado bajo polimorfismo molecular para las entradas analizadas, pero existe una alta variabilidad morfológica. En los agrupamientos, tampoco se forman grupos de acuerdo a la procedencia geográfica, lo cual es debido posiblemente al intercambio genético entre sus genotipos.

Las entradas UNALM-18 y UNALM-6 tuvieron más altos rendimientos con 1.458 .4 y 1.451 .6 t/ha respectivamente. El mayor volumen de granos reventados fue para la entrada UNALM-15, seguido de UNALM-19 con 10.11 y $9.46 \mathrm{ml}$ respectivamente. Los que presentaron buena calidad de grano tostado (buena cualidad y consistencia) y mayores porcentajes de expansión de grano reventado fueron las entradas UNALM-18, UNALM-15 y UNALM-19, con $177.72,174.37$ y $171.96 \%$ respectivamente. Estas entradas tienen alta potencialidad para su explotación comercial, las que deberán ser priorizadas en los programas de mejoramiento genético para generar nuevas variedades según las demandas de mercado y situaciones agronómicas. Esto puede generar mayores divisas y mejorar las condiciones de vida de los agricultores en la región andina.

\section{LITERATURA CITADA}

ALVARADO, Z. 1997. Caracterización y correlación fenotípica del fríjol reventón (Phaseolus vulgaris L.), en la localidad de Caracancha (Huarochiri-Lima). Tesis Ing. Agrónomo. UNALM. Lima - Perú. 165 p.

BEEBE, S.; J. RENGIFO; E. GAITÁN; M. C. DUQUE, AND J. TOHME. 2001. Diversity and Origin of Andean Landraces of Common Bean. Crop Sci. 41:854-862.
BLAS, R.; J. RIBAUT; M. WARBURTON; J. CHURA \& R. SEVILLA. 2002. Análisis molecular de razas de maíz peruano con marcadores AFLP y Microsatélites. En Simposiun "El mejoramiento genético de las plantas en el Perú”. Sociedad Peruana de Genética (3): 241-250 p.

CAMARENA F.; A. CERRATE; Y A. HUARINGA. 1990. El fríjol reventón "numia", "ñuña" o "apa". Revista INIAA. Lima -. Perú. 47 p. 
CENTRO INTERNACIONAL DE AGRICULTURA TROPICAL (CIAT). 1980. Informe Anual Programa de Fríjol. Cali, Colombia. 399 p.

CENTRO INTERNACIONAL DE LA PAPA (CIP). 1998. Protocolos de laboratorio de Biología Molecular. Tipificación Genética. Ghislain M., Zhang D., and Herrera, M.R. (Eds). Departamento de Recursos Genéticos. Manual de Capacitación. 2a Edición (Revisada Oct. 1998). Lima, Perú. 40 p.

CRISCI, J. \& M. LÓPEZ. 1983. Introducción a la teoría y práctica de la taxonomía numérica. Serie de biología № 26, Secretaría General de la Organización de los Estados Americanos (OEA). Programa Regional de Desarrollo Científico y Tecnológico. Washington D.C. 132 p.

DOYLE, J.J. \& J.L. DOYLE. 1990. Isolation of plant DNA from fresh tissue. Focus 12:13-15.

GAMARRA, F.; J. PUMA; J. ARANA. 1996. “Q'osco Poroto INIA- primera variedad de fríjol reventón para los Valles Interandinos de la Sierra - Cuzco", boletín técnico.

GALLEGOS, L. 1988. Caracterización fenotípica de 22 variedades de frijol (Phaseolus vulgaris L.), Tipo Ñuña en la Costa Central. Tesis Ing. Agr. Universidad Nacional Agraria La Molina. Lima - Perú. 133 p.

GHISLAIN, M.; D. ZHANG; D. FAJARDO; Z. HUAMÁN; R. HIJMANS. 1999. Marker assisted sampling of the cultivated Andean potato Solanum phureja collection using RAPD markers. En Genetic Resources and Crop Evolution 46: 547-555 p.

GÓMEZ O. J.; M. W. BLAIR; B. E. FRANKOW-LINDBERG, AND U. GULLBERG. 2004. Molecular and Phenotypic Diversity of Common Bean Landraces from Nicaragua. Crop Sci. 44:1412-1418.

HALWARD, T.; T. STALKER; E. LARUE; AND G. KOCHERT. 1992. Use of single primer DNA amplifications in genetic studies of peanut (Arachis hypogea L.). Plant Mol. Biol. 18:315-325.

INTERNATIONAL BOARD PLANT GENETIC RESOURCES (IBPGR). 1982. Descriptors for Phaseolus vulgaris L. Roma, Italia. $32 \mathrm{p}$.

JUGENHEIMER R.W. 1981. Maíz Variedad mejorada, métodos de cultivo y producción de semilla. $1^{\text {a }}$ Edición. Editorial Limusa, México D.F., 841 p.
KHANDKA, D.; A. NEJIDAT \& A. GOLAN-GOLDHIRSH. 1996. Polymorphism and DNA markers for asparagus cultivars identified by random amplified polymorphic DNA. Euphytica 87:39-44.

LLIQUE, N. 1993. "Efecto del medio ambiente en el contenido de proteínas y capacidad reventón del Fríjol Ñuña (Phaseolus vulgaris L.), en el Departamento de Cajamarca. Tesis Ing. Agr. Universidad Nacional de Cajamarca. Cajamarca, Perú. 81 p.

MARTíNEZ, C. 1991. Estudio de diferencias bromatológicas entre Frijol común (Phaseolus vulgaris L.) y Ñuña (Phaseolus vulgaris L.) en el Departamento de Cajamarca. Tesis Ing. Agr. Universidad Nacional de Cajamarca. Cajamarca, Perú. $76 \mathrm{p}$.

MARTíNEZ, O. 1995. Métodos estadísticos multivariados en biología molecular y su aplicación en investigación agrícola. Agronomía colombiana 12(1):66-71.

MELÉNDEZ,A. 1965. Ensayo comparativo de 4 variedades de frijol reventón en Lima. Tesis UNALM. Lima - Perú. 64 p.

NATIONAL RESEARCH COUNCIL. 1989. Nunas-popping beans. In: Lost Crops of the Incas. Little Known Plants of the Andes With Promise for Worldwide cultivation. National Academy Press. Washington D.C. p. 172-179.

ROHLF, F. 2000. NTSYS PC: Numerical Taxonomy and Multivariate Analysis for the IBM PC Microcomputers (and compatibles), version 2.1 User guide. Applied Biostatistics Inc. Stony Brook, New York, USA. 39 p.

TOHME, J.; O.TORO, J. VARGAS, Y D.G. DEBOUCK. 1995. Variability in Andean Ñuña Common Beans (Phaseolus vulgaris, Fabaceae). En Econ. Bot. p. 78-95.

TORO, O.; J. TOHME Y D.G. DEBOUCK. 1990. Wild bean (Phaseolus vulgaris L.): description and distribution. CIAT, Cali, Colombia.

VAN BEEM, J.; J. KORNEGAY \& L. LAREO. 1992. "Nutritive Value of the Nuña Popping Bean". En Econ. Bot. 46 (2): 164-170.

WILLIAMS, J.; H. HANAFEY; J. RAFALSKI \& S. TINGEY. 1993. Genetic Analysis Random Amplified Polymorphic ADN Markers. In Methods in enzymology. Academic Press. Inc 218 (51): 704-740.

ZIMMERER, C. 1986. "La Ñuña”. En V Congreso Internacional de Sistemas Agropecuarios Andinos, CODE PUNO, INIPACIPA XV. Puno - Perú. 